\title{
A Concrete Weather Reporting System Model using IoT
}

\author{
A. Sravani ${ }^{1}$, Ch. Sudhakar ${ }^{2}$ and N. Thirupathi $\operatorname{Rao}^{3}$, \\ Debnath Bhattacharyya ${ }^{4}$ and Tai-Hoon Kim ${ }^{5 *}$ \\ ${ }^{1,2,3,4}$ Department of Computer Science \& Engineering, Vignan's Institute of \\ Information Technology (A), Visakhapatnam, AP, India \\ ${ }^{5}$ Sungshin Women's University, Bomun-ro 34da-gil, Seongbuk-gu, Seoul, Korea \\ ${ }^{1}$ sravani61sravz@gmail.com,4debnathb@gmail.com, ${ }^{5 *}$ taihoonn@daum.net
}

\begin{abstract}
The framework projected in the current article is a propelled answer for recovering the ecological circumstances like temperature and mugginess at a precise position and create the information accessible anywhere on the world. The improvement utilized as a part of this paper is Internet of Things (IoT), is the idea of essentially interfacing any gadget with an on and off change to the Internet. Here things might be whatever like electronic contraptions, sensors and auto electronic rigging. The structure oversees watching and retrieving the common parameters like heat, comparative humidity, normal power and CO level with feeler and propel the data to the site sheet and a while later plan the feeler information as graphical experiences. The information revived from the executed model can be accessed in the web from wherever on the world.
\end{abstract}

Keywords: IoT System, Arduino UNO, Arduino Software, ESP8266

\section{Introduction}

The web allowed us to interface in ways we could never have envisioned possible. The Internet of Things suggests the limit of common things to connect with the Internet and to each other through little, introduced sensors and wired and remote advances. For customers, the IoT can pass on courses of action that altogether improve essentialness viability, security, prosperity, preparing and various diverse parts of consistently life. For wanders, IoT can bolster plans that upgrade fundamental administration and proficiency in collecting, retail, cultivation and distinctive parts [5]. Show progressions in growth dominatingly focal point on reducing and recuperating of various activities. These rose to achieve most by far of the human needs. Whenever the sensors in the network are entering into the situation or the position, then the condition of the sensors in the network will become as contraption mode and the microcontrollers in the unit will become the programming purpose transformation into the self-securing and self-watching condition [9].

The fuss and CO levels are checked as, if any limitation observes crossing its border observe ranges, for example $\mathrm{CO}$ levels in air in a meticulous district outperforming the average levels et cetera, in the earth using remote introduced figuring structure is proposed in this paper. It similarly gives a keen remote checking to a specific region of interest. In this paper we also fused the grades of assembled information by means of the common place or decided extents of exacting limitations. The surrounded system is a compromise of sensor devices, remote correspondence which allow the customer to remotely get to the distinctive limitations and amass the information in cloud. The upsides of this application are that we can have the passage of the data concerning the temperature

Received (September 19, 2017), Review Result (January 10, 2018), Accepted (January 16, 2018)

* Corresponding Author 
and stickiness around us from wherever on the planet without much fight. Furthermore, we can see the data in various structures, instance, tables and charts et cetera.

\section{Existing System}

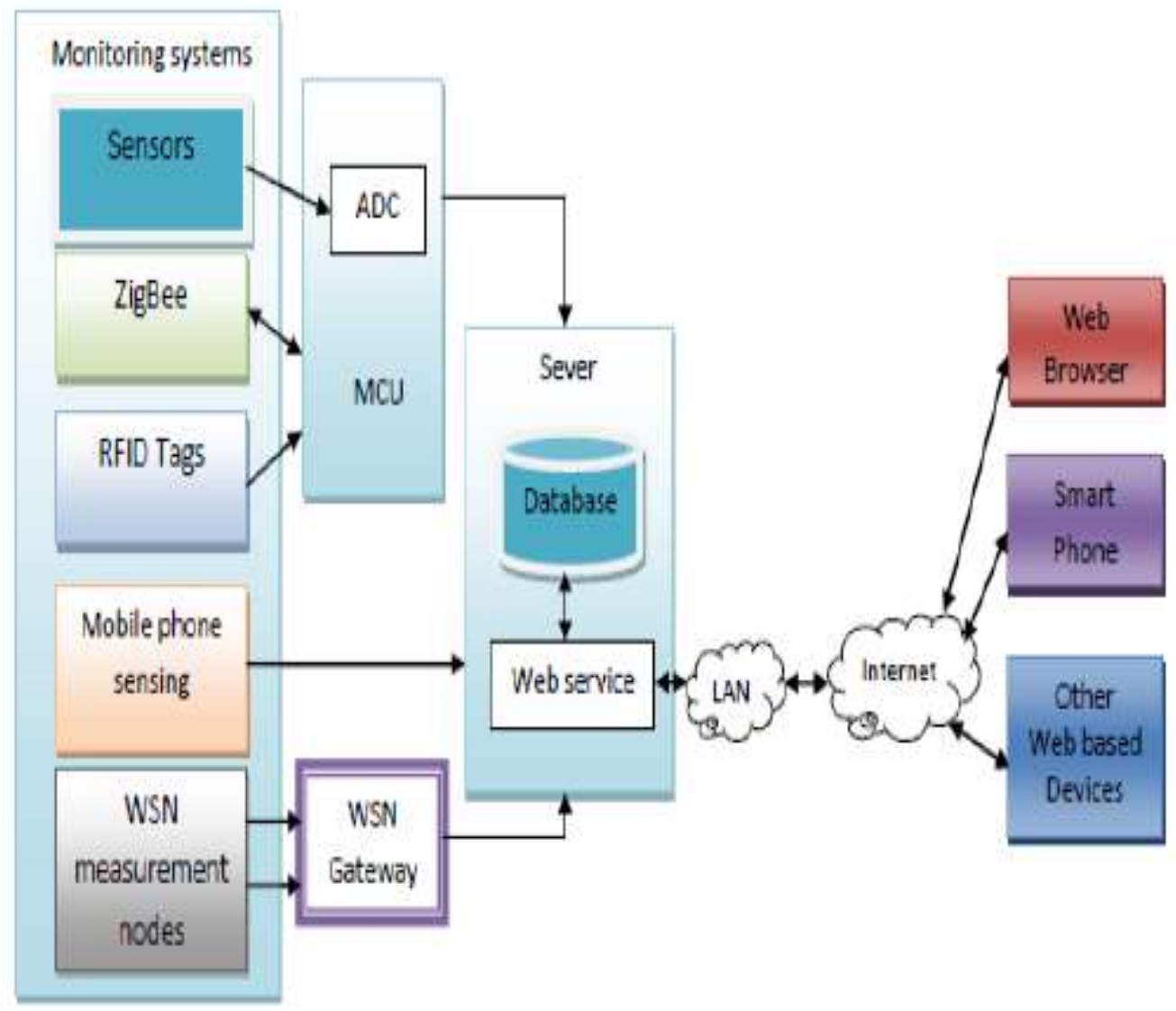

Figure 1. Existing System Model

Existing framework display is exhibited in Figure 1 utilizes Zigbee [3] based remote sensor systems to screen physical and natural conditions with a large number of use in various fields. The sensor hubs straightforwardly spoke with the moving hubs conveyed on the question of intrigue which maintained a strategic distance from the utilization of complex steering calculation however neighborhood calculations are extremely negligible. The peer user can read and additionally compose information to labels by means of remote transmissions. In a normal RFID application, labels are connected or inserted into objects that need recognizable proof or following.

Advanced cells [5] that are empowered with sensors are utilized for affect on social including how portable innovation must be utilized for natural securing, detecting and to impact without a moment to spare data to make developments and activities ecological inviting. Cell phone sensors were conveyed and utilized on urban zones for checking and it was arranged into two noteworthy lessons, participatory detecting where client is specifically included and astute detecting where client isn't included, yet its impediment incorporates power and static data handling or portability limitations. A WSN [6] comprises of numerous modest remote sensors, which are equipped for gathering, putting away, handling natural data, and speaking with neighboring hubs. Previously, sensors are associated by wire lines. 


\section{Proposed Work}

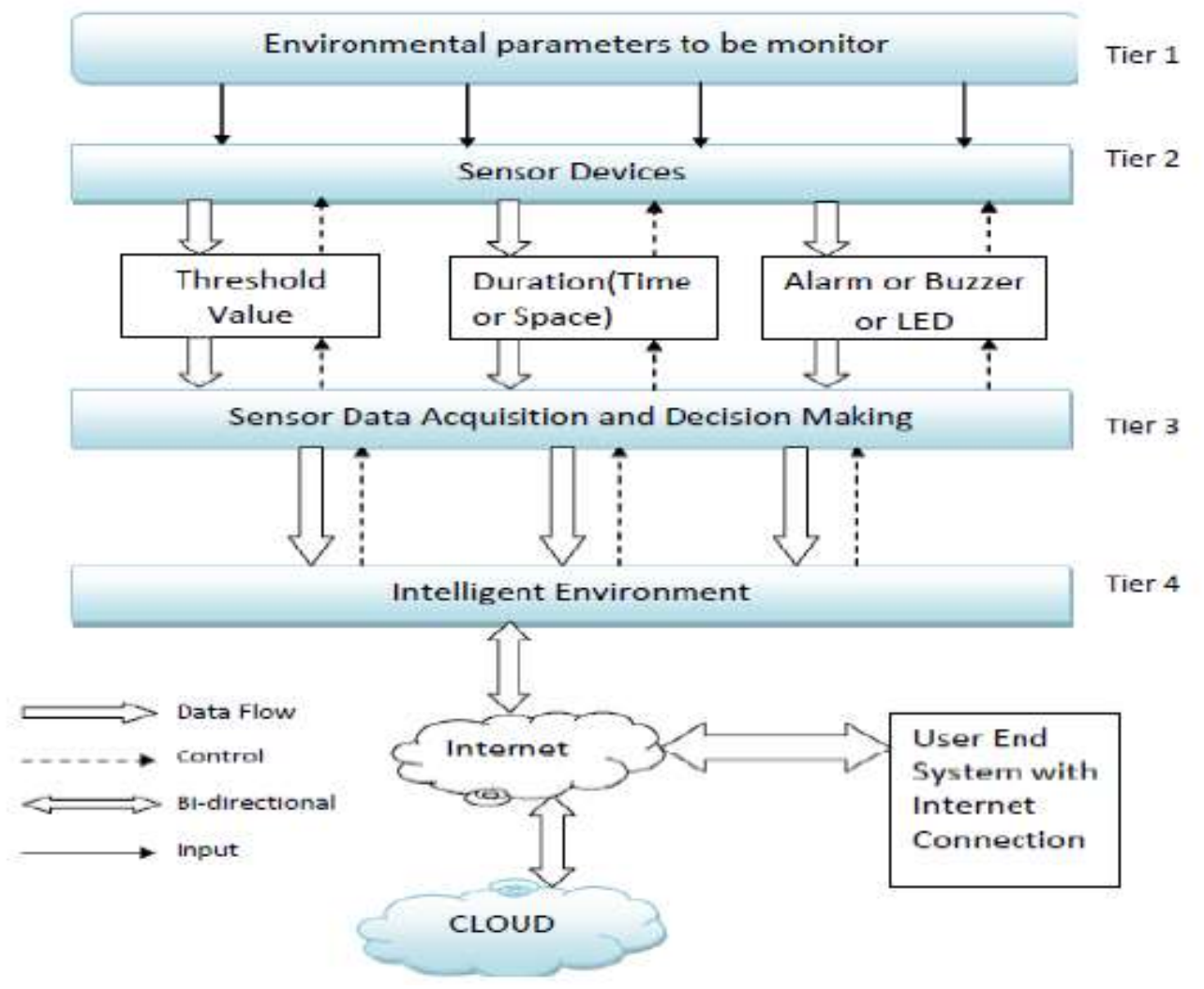

Figure 2. Proposed Model

The planned engineering is examined in a 4-level model with the elements of every personage units created for climate observing framework. The proposed display comprises of 4-levels. The level 1 is the earth, sensor gadgets in level 2, sensor information securing and basic leadership in level 3 and Arduino programming IDE in level 4 . The level 1 gives data about the parameters under the district which is to be observed for temperature and mugginess. Level 2 manages the sensor gadgets with reasonable qualities, highlights and each of these sensor gadgets are worked and controlled in light of their affectability and in addition the scope of detecting. In the middle of level 2 and level 3 important detecting and controlling moves will be made relying on the conditions, such as settling the limit esteem, periodicity of detecting, messages (alert or ringer or LED or sensor) and so on.

Level 3 portrays about the information securing from sensor gadgets and furthermore incorporates the basic leadership. Which indicate the condition the information is speaking to which parameter. In the proposed demonstrate level 4 manages the smart condition. Which implies it will distinguish the varieties in the sensor information and fix the edge esteem contingent upon the recognized level of $\mathrm{CO}$ or commotion levels. Furthermore, it will demonstrate a pattern of the detected parameters as for the predetermined esteems. The end clients can peruse the information utilizing cell phones, PCs and so on. 


\subsection{Flow Diagram}

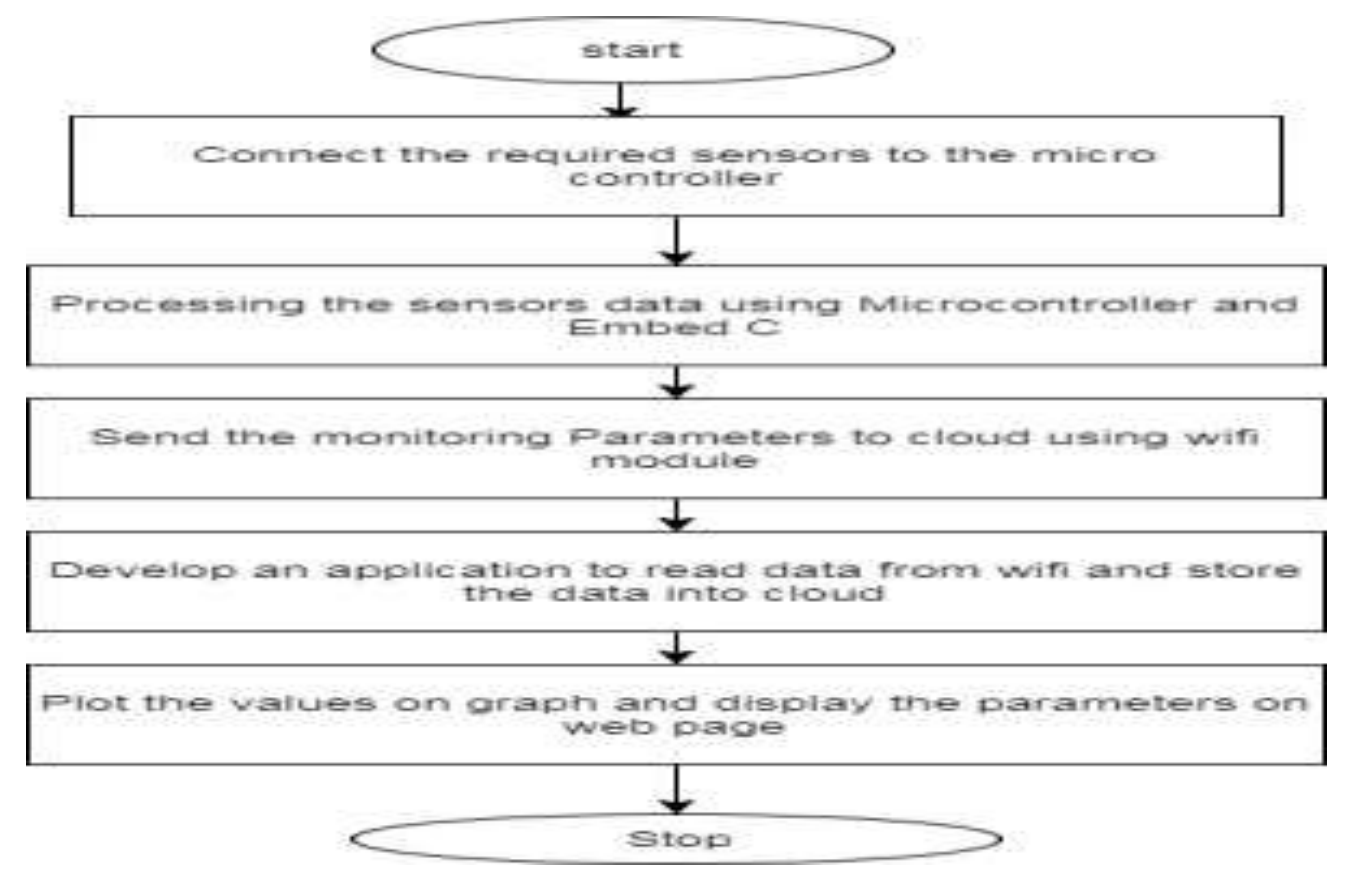

Figure 3. Flow Diagram of the Proposed Model

\subsection{Implementation Model}

The Wi-Fi association must be set up to exchange sensors information to end client and furthermore send it to the distributed storage for future utilization.

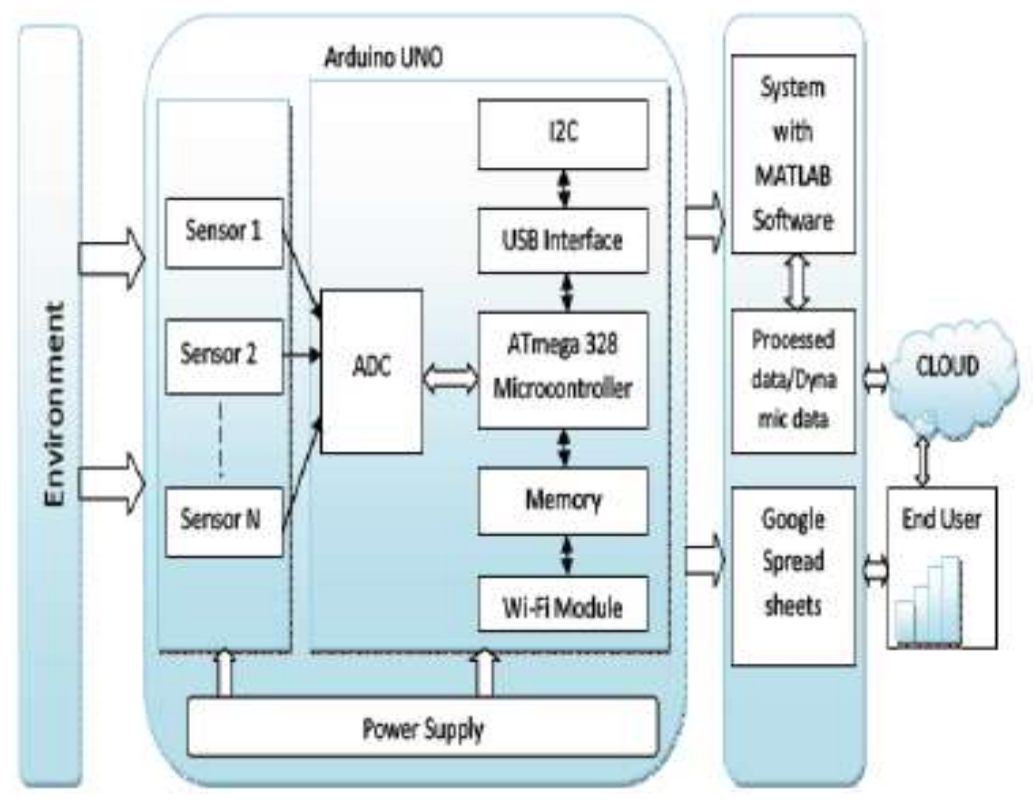

Figure 4. Schematic Diagram of Implementation Model

An inserted framework intended for natural observing and its segments are appeared in Figure 5. The installed gadget is put specifically region for testing reason. The sound sensor will collect sound power levels around there and Carbon Monoxide (CO) sensor MQ-9 will record the air quality in that area, if as far as possible is crossed the relating 
controlling move will be made. All the sensor gadgets are associated with web through Wi-Fi module.

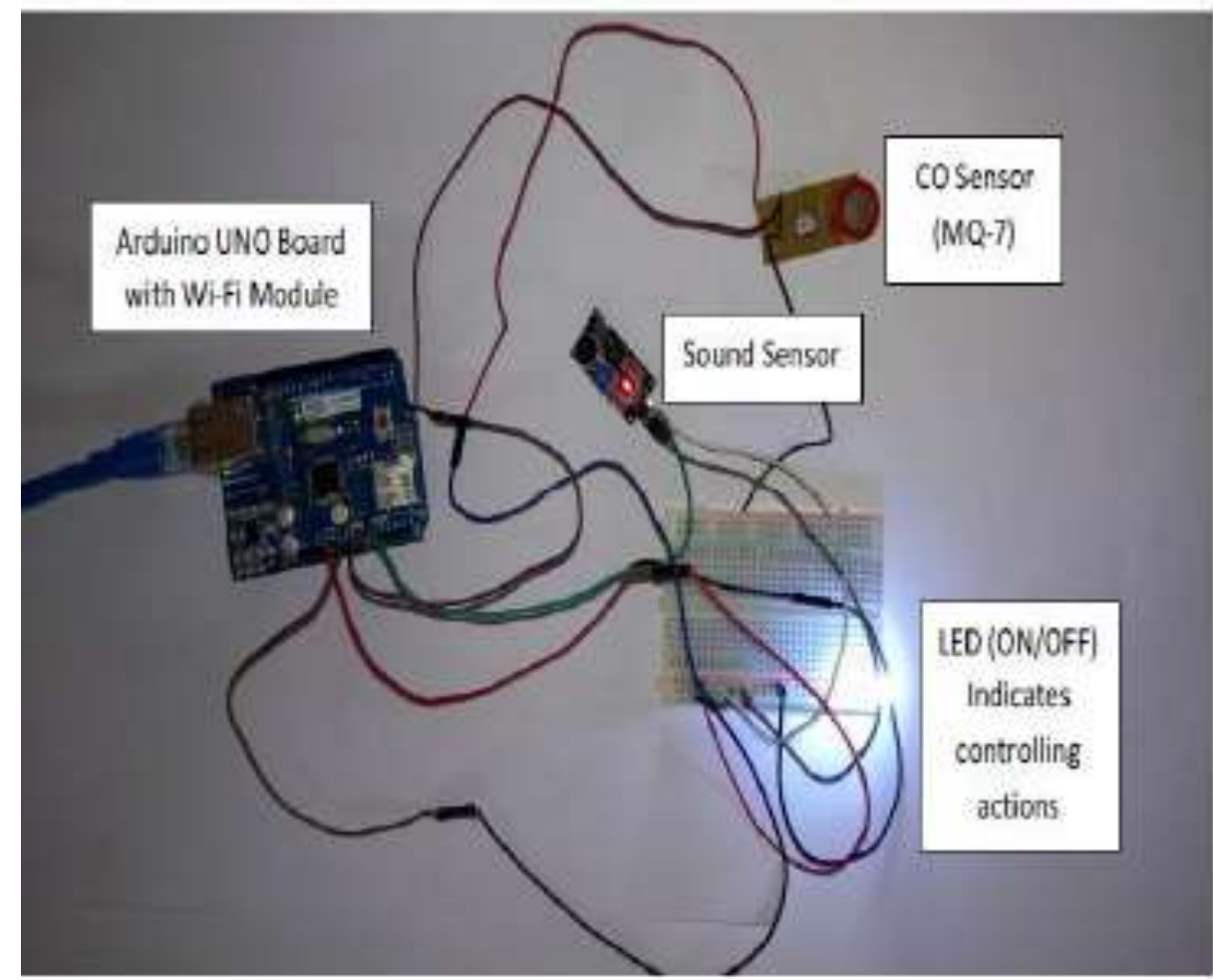

Figure 5. Commotion and Air Contamination Observing Inserted Framework with its Parts

\section{Results}

Once the system is connected to system, we can see the output in the Serial monitor of Arduino UNO IDE. It displays all temperature and Humidity values temperature sensor as shown in the Figure 7.

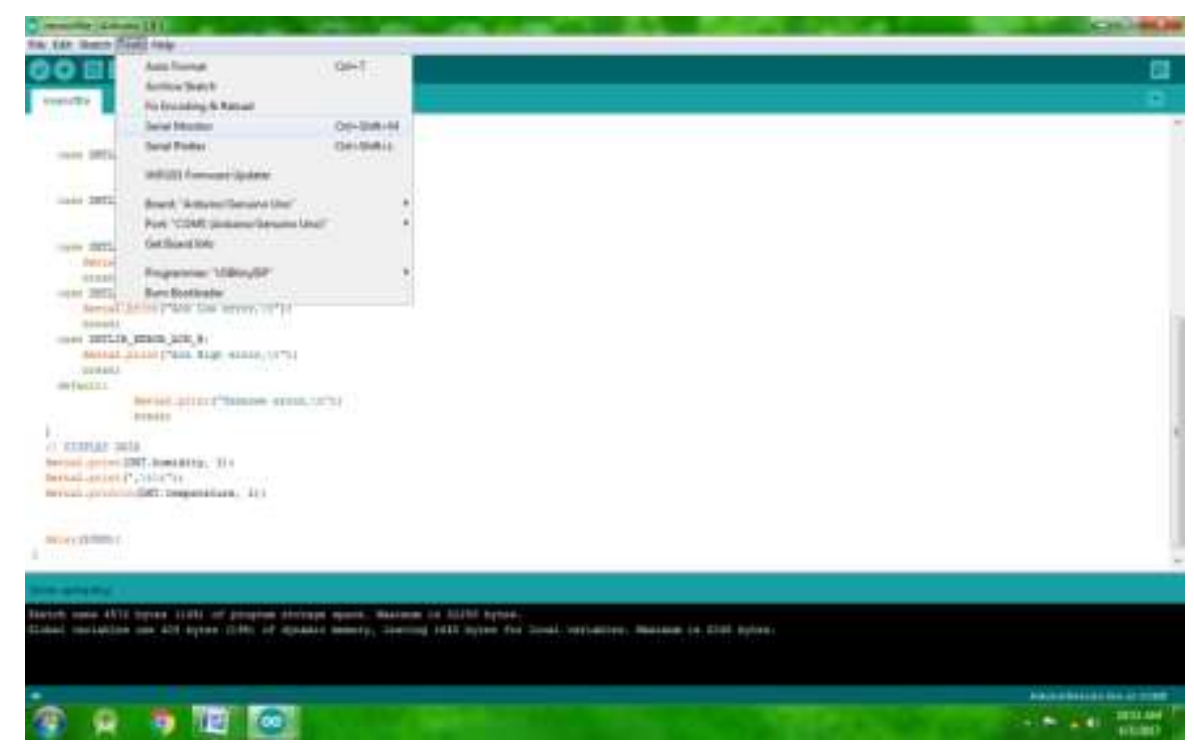

Figure 6. Selection of Serial Monitor in Arduino IDE 


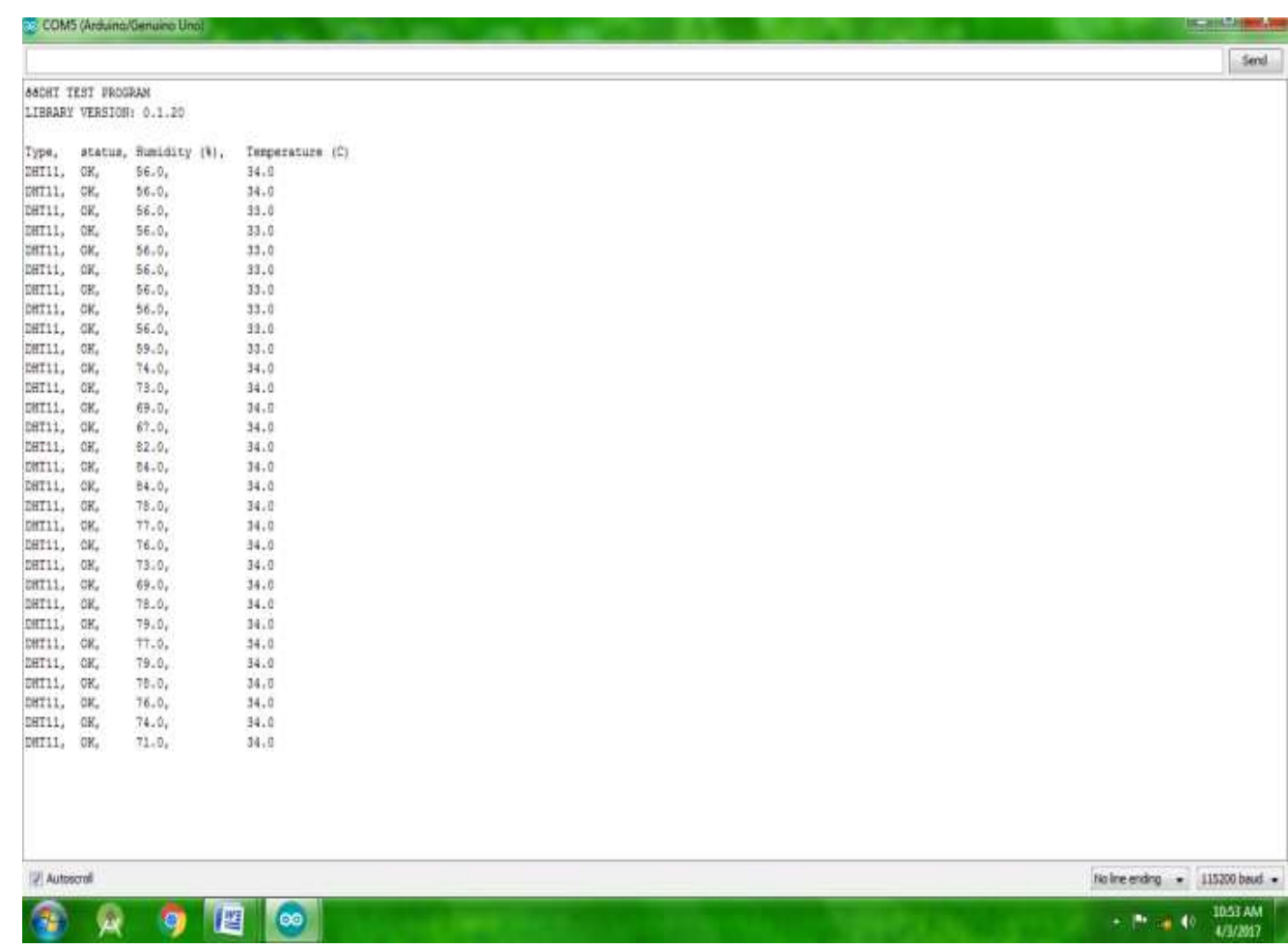

Figure 7. Screen Shot Showing Temperature and Humidity

The Serial Plotter gives the graphical representation of temperature and humidity values for the duration of 250 seconds. The blue line represents humidity and red line represents temperature. It is shown in the Figure 8.

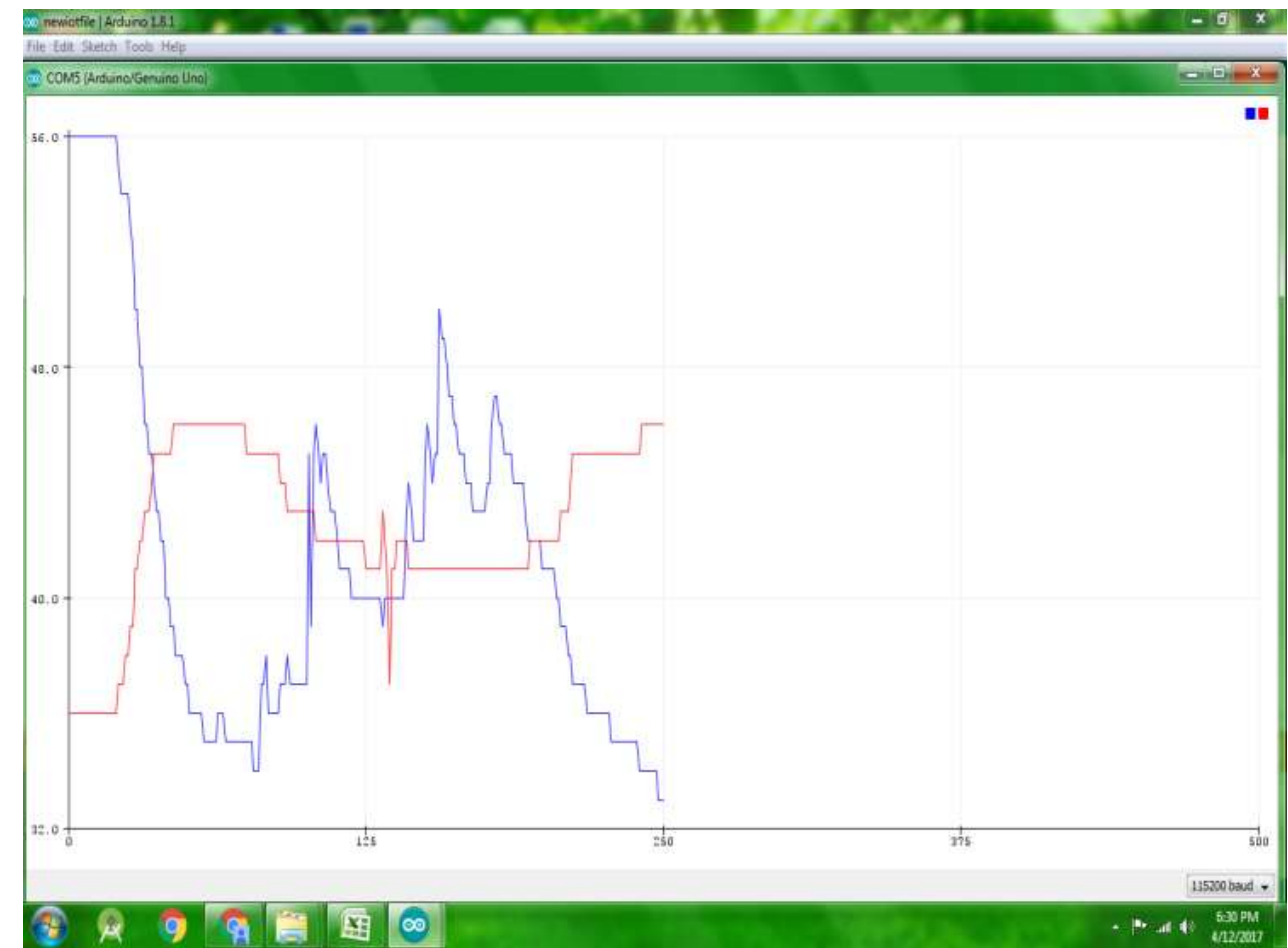

Figure 8. Serial Plotter of Temperature and Humidity 
The Figure 9 demonstrates the data about the force of sound and the $\mathrm{CO}$ level varieties in that specific district, where the installed observing framework is set.

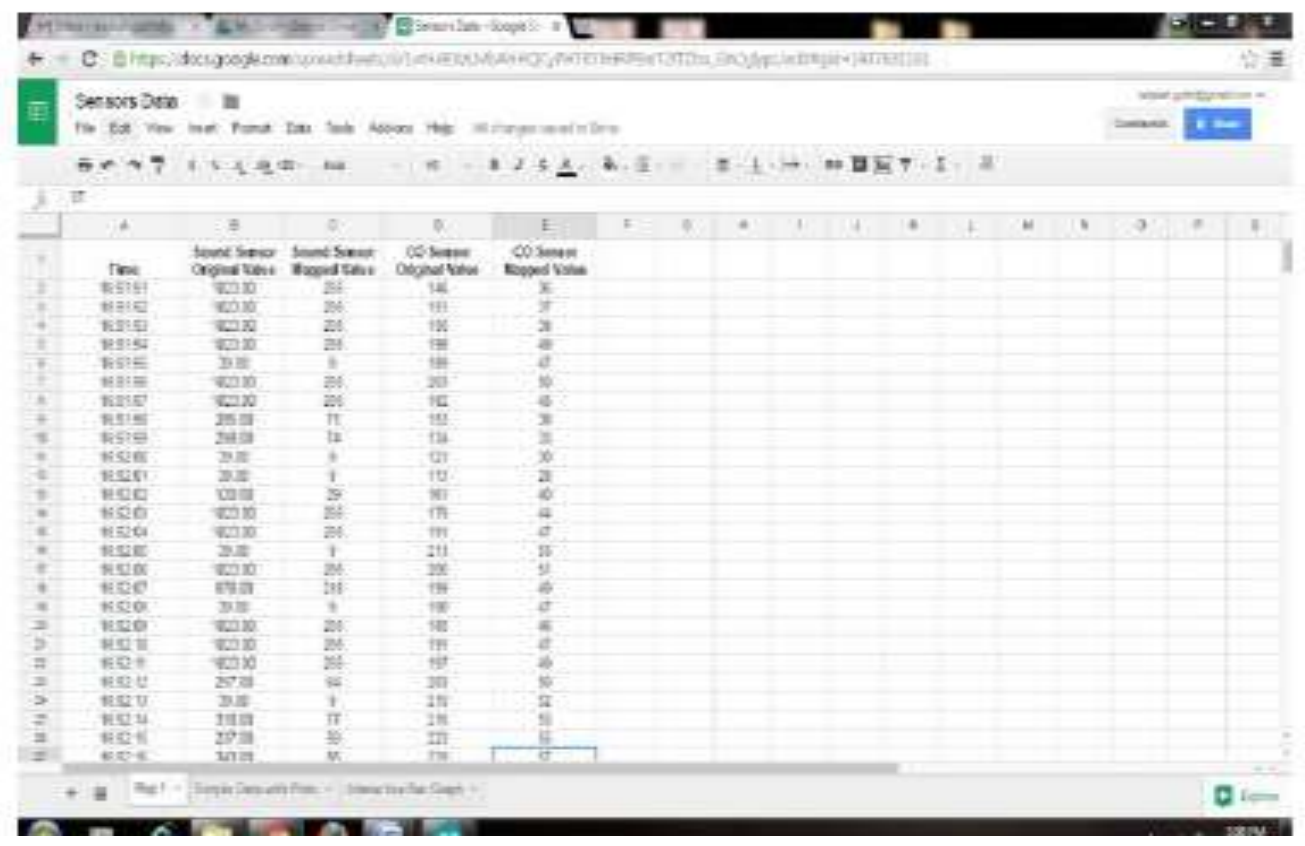

Figure 9. Sensors Data Stored in Cloud

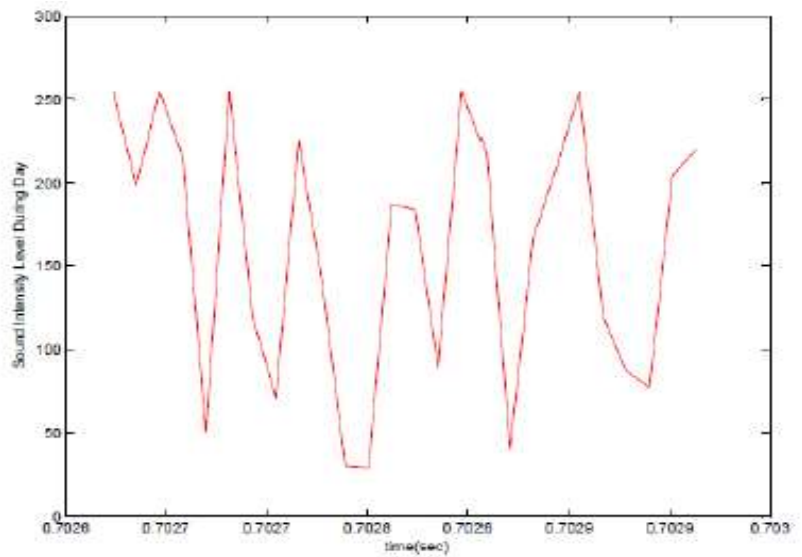

Figure 10(a)

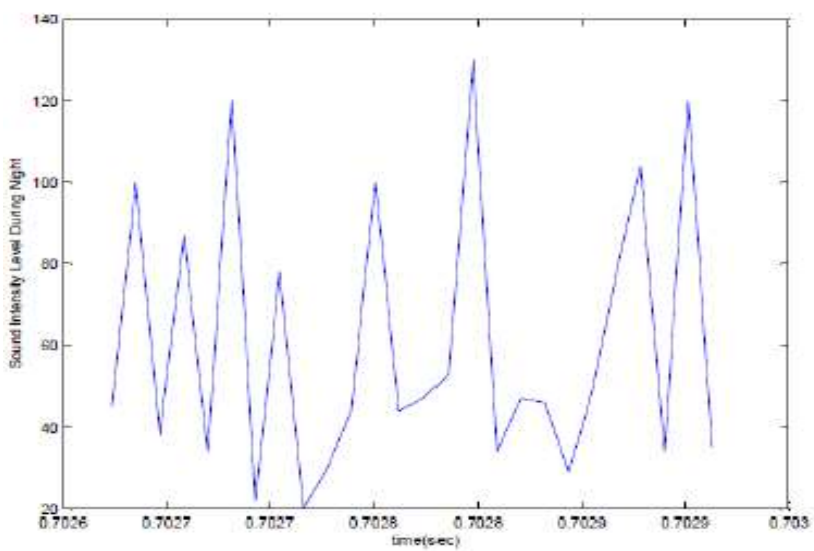

Figure10(b) 


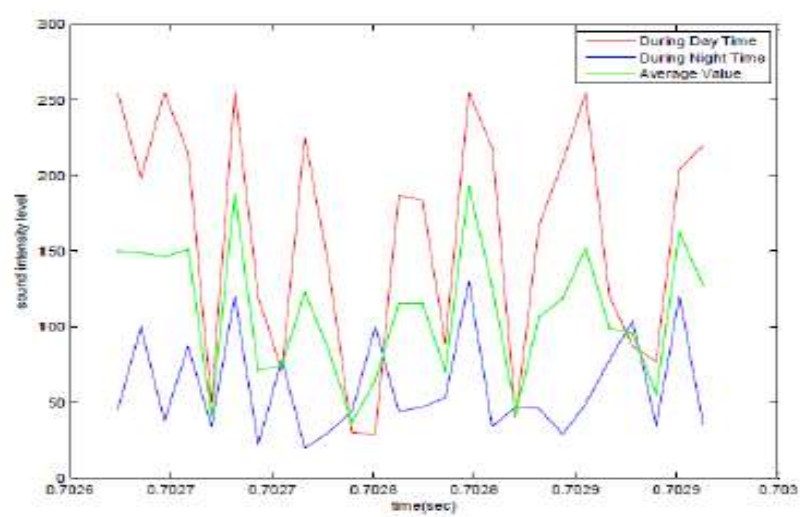

Figure 10(c)

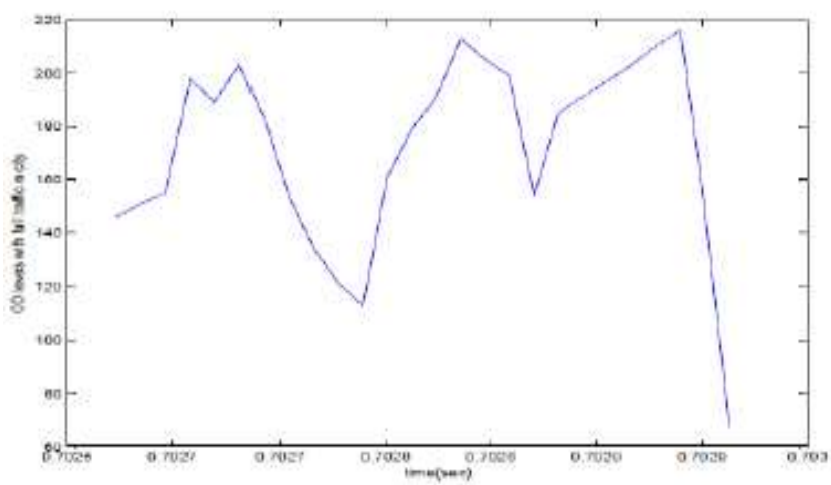

Figure 11(a)

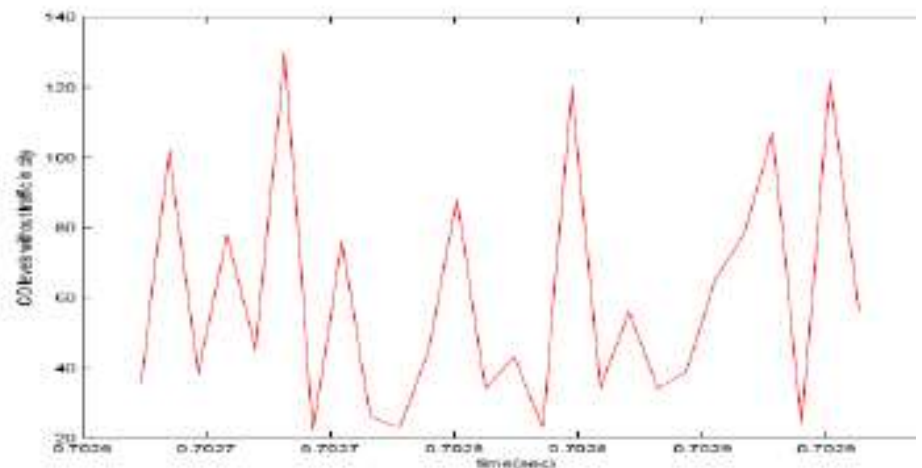

Figure.11(b)

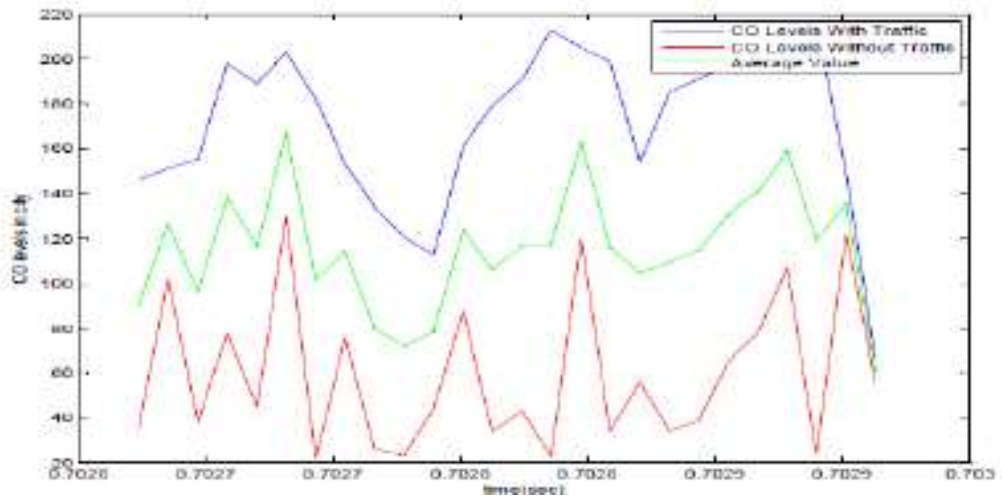

Figure.11(c) 
The outline in figure 10 (an) exhibits the sound power levels in the midst of day time at standard time between times. The graph 10 (b) shows the sound power levels in the midst of night time. The diagram 10(c) exhibits the ordinary sound power levels in the midst of entire day. Dependent upon the typical regard, confine regard will be picked. The outline in figure 11(a) shows the CO levels in city condition with full action at standard time intervals. The chart 11(b) exhibits the $\mathrm{CO}$ levels in city condition without movement. The graph 11(c) exhibits the ordinary CO levels in the midst of entire day. In the wake of completing the examination on distinguished data, the cutoff regard will be set for imperative controlling exercises.

\section{Conclusion}

We developed a weather reporting system, by making use of a ESP8266 wifi module, Corbon Monoxide(CO) sensor to sense the CO concentration in the outside world, LM35 sensor to read temperature, Sound sensor to detect decibel level, and an Light Dependent Resistor (LDR) which can change light intensity basing on circumstances. This paper is used for knowing environmental parameters like temperature and humidity. The sensors have been incorporated with the arrangement to observe and calculate the height of extinction of heat and moisture in the atmosphere. This application enables self protection to the environment. When we are sending the sensor gadgets in the earth, we can bring nature into genuine. The savvy approach to screen condition and a proficient, minimal effort installed framework is given diverse models in this paper.

\section{References}

[1] L. Atzori, A. Iera and G. Morabito, "The internet of things: A survey", Comput. Netw., vol. 54, no. 15, (2010), pp. 2787-2805.

[2] J. P. Lynch and J. L. Kenneth, "A summary review of wireless sensors and sensor networks for structural health monitoring", Shock and Vibration Digest, vol. 38, no. 2, (2006), pp. 91-130.

[3] S. Lee, D. Yoon and A. Ghosh, "Intelligent parking lot application using wireless sensor networks", Proc. Int. Symp. Collab. Technol. Syst., (2008) May 19-23, pp. 48-57.

A. P. Castellani, N. Bui, P. Casari, M. Rossi, Z. Shelby and M. Zorzi, "Architecture and protocols for the Internet of Things: A case study", Proc. 8th IEEE Int. Conf. Pervasive Comput. Commun. Workshops (PERCOM Workshops), IEEE, (2010), pp. 678-683.

[4] P. Castellani, M. Dissegna, N. Bui and M. Zorzi, "WebIoT: A web application framework for the internet of things", Proc. IEEE Wireless Commun. Netw. Conf. Workshops, IEEE, (2012).

[5] P. Susmitha and G. Sowmyabala, "Design and Implementation of Weather Monitoring and Controlling System”, International Journal of Computer Applications (0975 - 8887), vol. 97, no. 3, (2014) July, pp. 19-22.

[6] H. A. P. K. Hettiarachchi and I. M. K. Fernando, "USB Based High Speed Data Acquisition System for an Unmanned Weather Station", 2nd Int. Conf. on e-governance, (2004).

[7] M. Moghavvemi and S. Tan, "A reliable and economically feasible remote sensing system for temperature and relative humidity measurement", Sensors and Actuators, (2005), pp. 181-185.

[8] B. Srinivas Rao, K. Srinivasa Rao and N. Ome, "Internet of Things (IOT) Based Weather Monitoring system", International Journal of Advanced Research in Computer and Communication Engineering ISO 3297:2007 Certified, vol. 5, no. 9, (2016) September.

[9] http://playground.arduino.cc/Main/DHT11Lib. 
International Journal of Control and Automation

Vol. 11, No. 4 (2018) 